\title{
RELAÇÕES ENTRE ENSINO E APRENDIZAGEM NA EJA
}

\section{José Moisés Nunes da Silva}

IFRN - Campus Natal Central. E-mail: jose.silva@cefetrn.br

\section{Valdenêr Avelino Correia}

IFRN - Campus Natal Central. E-mail: valdener@cefetrn.br

Charlon Silles de Souza Gomes

IFRN - Campus Natal Central. E-mail: charlon@cefetrn.br

Débora Ionara Rodrigues de Melo

IFRN - Campus Natal Central. E-mail: debora@cefetrn.br

\section{RESUMO}

Este artigo tem por objetivo apresentar uma distinção clara e objetiva entre os processos de ensinar e aprender. Nessa perspectiva, primeiramente destaca a educação no contexto e como parte integrante dos processos de transformações do mundo contemporâneo. Em seguida, sustentado por diversos autores, discute-se a distinção entre ensinar e aprender. Espera-se contribuir para uma reflexão sobre a prática pedagógica docente e da necessidade de melhoria do processo de ensino e aprendizagem a fim de possibilitar uma educação em consonância com a concepção de formação integral do cidadão, à medida que tal distinção seja introjetada pelos professores.

PALAVRAS-CHAVE: Ensinar. Aprender. Aprendizagem do jovem e do adulto. 


\section{RELAÇÕES ENTRE ENSINO E APRENDIZAGEM DA EJA}

\section{INTRODUÇÃO}

A temática desse artigo decorre das discussões em algumas disciplinas do curso de PósGraduação Lato Sensu em Educação Profissional Integrada à Educação Básica na Modalidade de Educação de Jovens e Adultos, no Instituto Federal de Educação, Ciência e Tecnologia do Rio Grande do Norte (IFRN), bem como da constatação de que a maioria dos professores, em todas as áreas do conhecimento, tem a concepção de que o ato de ensinar implica, necessariamente, no ato de aprender, como uma unidade inseparável, constatação essa, verificada pelos autores junto aos docentes do IFRN.

Respaldando-nos em Cunha (1982), Dowbor (1996), Freire (1996), Delors (1999), Piconez (2007), Ries (2007), Gadotti (1988) e Gadotti (2003), buscamos contextualizar a educação na sociedade contemporânea e demonstrar as diferenças conceituais entre ensino e aprendizagem, de sorte a contribuir com a prática docente no afã de tornar a relação ensino-aprendizagem com sentido para professores e alunos.

O texto está estruturado em três partes, além desta introdutória. Na primeira, aborda-se a educação no contexto contemporâneo. Na segunda, apresenta-se as diferenças entre ensino e aprendizagem. Na terceira e última parte, as considerações finais.

\section{A EDUCAÇÃO NO CONTEXTO CONTEMPORÂNEO}

A sociedade contemporânea marcada, sobretudo, a partir das três últimas décadas do século XX, pela revolução tecnológica - vale dizer, com pressupostos na informática e nas telecomunicações - é pautada em grande medida, pela globalização da economia.

Em termos globais, o impacto do progresso tecnológico e da globalização, levou a uma sociedade marcada por maior complexidade, maior diversidade e desigualdade, e ritmo de transformação extremamente rápido, exigindo respostas mais flexíveis e mecanismos participativos que envolvem todos os membros da sociedade.

Por outro lado, alavancou a promoção e o resgate da cidadania de grande massa de marginalizados, particularmente, em países subdesenvolvidos ou em desenvolvimento, com reflexos imediatos na educação, haja vista ter criado nos países uma base ampla de conhecimento, uma verdadeira revolução científica e cultural.

Até 1970, o paradigma era de que a educação, numa visão estreita, seria um instrumento destinado a adequar o futuro profissional ao mundo do trabalho, disciplinando-o e municiando-o com conhecimentos técnicos. A partir daí, o paradigma mudou. Agora, busca-se assegurar à educação uma autonomia que lhe permita centrar-se, além da profissionalização, nos valores humanos, na formação do cidadão, na leitura crítica e criativa de mundo, e assim chegar ao exercício de uma cidadania ativa.

Em consequência, atualmente, ninguém vive apenas com os conhecimentos adquiridos na juventude, até ao fim da vida, porque o mundo globalizado exige uma atualização contínua dos saberes, e uns saberes penetram e enriquecem os outros. 
Partindo das tendências constatadas em diversos países, Dowbor (1996) entende que, em termos de espaço do conhecimento, já não basta, hoje, trabalhar com propostas de modernização da educação; trata-se de repensar a dinâmica do conhecimento e dar novos enfoques a questão do universo de conhecimentos a trabalhar; implementar novas metodologias, o aprender a "navegar”; tornar mais palpável a noção de área especializada de conhecimentos, ou de "carreira"; resgatar a cidadania; enfim, evidenciar novas funções do professor como mediador deste processo.

A educação ao longo de toda a vida não é um ideal longínquo, mas uma realidade que tende, cada vez mais, a inscrever-se nos fatos, no seio de uma paisagem educativa complexa [...]. ... é preciso deixar de considerar as diferentes formas de ensino $e$ aprendizagem como independentes umas das outras [...] e procurar, pelo contrário, valorizar a complementaridade dos espaços e tempos da educação moderna. (DELORS, 1999, p. 104, grifo nosso).

É por isso que o impulso dado à educação básica - sobretudo quanto à universalização do acesso ao ensino fundamental: no Brasil, aproximadamente, 97\% das crianças de 7 a 14 anos têm acesso a esse nível de ensino (BRASIL, 2007) -, os progressos da alfabetização e o aumento de escolarização dos jovens e adultos, deixam antever o desejo de continuar a aprender: "quanto mais formado se é, mais desejo se tem de

formação, e esta tendência observa-se tanto em países desenvolvidos como nos países em desenvolvimento" (DELORS, 1999, p. 105).

Mas a aprendizagem - objetivo final da educação - não ocorre da mesma forma nos seres humanos, tanto que os adultos não aprendem da mesma maneira que as crianças, embora o ambiente tradicional de ensino - a escola - não tenha se modificado: hoje a escola é semelhante àquela que nossos avós frequentaram. As crianças aprendem para o futuro, enquanto os adultos aprendem para o presente.

A aprendizagem nos adultos passa por referenciais de: significação, compreensão inicial, ritmo, expectativas, participação, adequação e interdisciplinaridade (PICONEZ, 2007).

Por outro lado, ensinar e aprender são coisas bem distintas, embora, na prática, esteja arraigado entre os professores a idéia de que o ato de ensinar implica, necessariamente, no ato de aprender, numa perfeita simbiose. Entender essa distinção é o objetivo desse artigo.

\section{O ENSINO E A APRENDIZAGEM: DUAS COISAS DISTINTAS E INSEPARÁVEIS}

Parece óbvio dizer que ensinar e aprender são coisas distintas, mas não é. No cotidiano, muitos professores entendem que são a mesma coisa, que se eles ensinam, automaticamente os alunos aprendem. Ora, se isso fosse verdade, não se ouvia, após uma explicação (o ensino) do professor, o aluno dizer que não entendeu, não aprendeu.

Certamente o ensino visa à aprendizagem. Mas, pode haver ensino sem aprendizagem - 0 que é bastante comum no sistema educativo, como também aprendizagem sem ensino - o aluno estuda por conta própria, é um autodidata. Isto nos remete a constatação da afirmação inicial, assim como ao fato de que ensinar e aprender são processos diferentes que envolvem sujeitos também diferentes num diálogo constante. 
“Toda prática educativa demanda a existência de sujeitos, um que, ensinando, aprende, outro que, aprendendo, ensina” (FREIRE, 1996, p. 69).

Etimologicamente, ensinar deriva do latim insignare, que significa indicar, designar, marcar, assinalar (CUNHA, 1982). Assim, pode-se entender ensinar como marcar com um sinal, no sentido de instruir sobre, mostrar algo a alguém. $O$ professor aponta ao aluno o significado das coisas, assinalando o que julga importante, marcante, distinto. Nessa perspectiva, "ensinar exige apreensão da realidade” (FREIRE, 1996, p. 68), exige problematizar o mundo em que vivemos para superar as contradições, comprometendo-se com esse mundo para recriá-lo constantemente (GADOTTI, 1988).

Ensinar não é, pois, transmitir conhecimento e, sim, emitir novos signos, propiciando ao outro sujeito condições para que desenvolva as condições básicas de domínio das diversas linguagens, sobretudo a materna, sistematizando o conhecimento e se apropriando dele para a vida.

Já aprender vem do latim apprehendere, que quer dizer apreender, apanhar, apropriar, apossar-se de, adquirir conhecimento, tomar para si o conteúdo ensinado (CUNHA, op cit). Nesse sentido, o ato de aprender pressupõe permanência, ou seja, "o indivíduo que aprende fica marcado pelo processo” (RIES, 2007, p. 24).

Aprender implica na capacidade do sujeito de construir e reconstruir significados, que se traduz em mudanças no seu conhecimento de mundo e no conhecimento de si mesmo como sujeito histórico, mediante a formulação de questionamentos, observações, de análise e síntese das descobertas, na maneira de ser, pensar, sentir, perceber e compreender, de forma duradoura (FREIRE, 1996; GADOTTI, 2003; RIES, 2007).

É na dinâmica da interação ensino-aprendizagem que "só aprende verdadeiramente aquele que se apropria do aprendido, construindo e re-construindo seus significados, podendo por isso mesmo reinventá-lo” (PICONEZ, 2007, p. 3, grifo do autor).

Existem várias teorias de aprendizagem, todas buscando reconhecer a dinâmica envolvida nos atos de ensinar e aprender, e explicar a relação entre o conhecimento pré-existente e o novo conhecimento. Todavia, todas admitem que aprender equivale a modificar comportamentos.

Assim, "para que se possa falar em aprendizagem, isto é, para que possa dizer que o indivíduo aprendeu, deve-se observar no seu comportamento uma mudança real e permanente” (PICONEZ, 2007, p. 4).

\section{CONSIDERAÇÕES FINAIS}

Na perspectiva das reflexões apresentadas neste artigo, podemos afirmar que o ato de aprender está intimamente associado ao ato de ensinar, que ensinar e aprender são processos dialéticos e como tais, implicam em uma ação colaborativa, participativa e de construção conjunta, mediante interação de experiências, não só entre professores e alunos, como também entre alunos, e que a aprendizagem é um processo contínuo e absolutamente necessário para toda a vida. 
Todavia, enquanto a maioria dos professores não tiver clareza de que ensinar e aprender são coisas distintas, certamente o processo ensino-aprendizagem, ou em sentido amplo, a educação, continuará mostrando a sua face de má qualidade e as gritantes desaprendizagens dos alunos.

Enquanto ensinar é marcar, mostrando algo efetivamente a alguém, aprender é tomar para si esse algo ensinado, de forma significativa e duradoura.

Comungamos com Paulo Freire quando afirma: “Quem ensina aprende ao ensinar e quem aprende ensina ao aprender” (FREIRE, 1996, p. 25).

Por isso, para o educador ensinar com qualidade, ele precisa, além de dominar a sua prática, “ter clareza do que é aprender, do que é 'aprender a aprender', para (entender) melhor o ato de ensinar. [...]. (É preciso) saber o que é ensinar, o que é aprender e, sobretudo, como aprender” (GADOTTI, 2003, p.48).

\section{REFERÊNCIAS BIBLIOGRÁFICAS}

BRASIL. Ministério da Educação. Programa nacional de integração da educação profissional com a educação básica na modalidade de educação de jovens e adultos PROEJA. Formação Inicial e Continuada/Ensino Fundamental. Documento Base, 2007. Disponível em <http://portal.mec.gov.br/setec/arquivos/pdf2/proeja_fundamental_ok.pdf> Acesso 10.10.2008.

CUNHA, Antônio Geraldo da. Dicionário etimológico nova fronteira da língua portuguesa. 2. ed. Rio de Janeiro: Nova Fronteira, 1982.

DOWBOR, Ladislau. Educação, Tecnologia e desenvolvimento. In: BRUNO, Lucia (Org). Educação e Trabalho no Capitalismo Contemporâneo. São Paulo: Atlas, 1996, p. 17-40.

FREIRE, Paulo. Pedagogia da autonomia. São Paulo: Paz e Terra, 1996.

GADOTTI, Moacir. Educação e poder: introdução à pedagogia do conflito. 8. ed. São Paulo: Cortez,1988.

Boniteza de um sonho: ensinar-e-aprender com sentido. Novo Hamburgo (RS): Feevale, 2003. Disponível em:

http://www.recid.org.br/index.php?option=com_remository\&Itemid=76\&func=fileinfo\&id $=1$. Acesso 02.07.2009.

PICONEZ, Stela C. Bertholo. A aprendizagem do jovem e do adulto e seus desafios fundamentais. Texto disponibilizado na Webteca do site do Núcleo de Estudos em Educação de Jovens e Adultos e Formação Permanente de Professores. www.nea.fe.usp.br. Acesso 20.09.2007.

RIES, Bruno. A aprendizagem na fase adulta. Texto disponibilizado na Webteca do site do Núcleo de Estudos em Educação de Jovens e Adultos e Formação Permanente de Professores. www.nea.fe.usp.br. Acesso 20.09.2007. 